\title{
Traditional Music as a Sustainable Social Technology for Community Health Promotion in Africa: "Singing and Dancing for Health" in Rura Northern Ghana
}

\author{
Michael Frishkopf \\ Faculty of Arts \& Faculty of Medicine and Dentistry, \\ University of Alberta, Canada \\ michaelf@ualberta.ca
}

\begin{abstract}
David Zakus
Faculty of Community Studies, School of Occupational and Public Health, Ryerson University, Canada

dzakus@ryerson.ca
\end{abstract}

Hasan Hamze

Independent Researcher,

British Columbia, Canada

hamze@ualberta.ca

Mubarak Alhassan

Grooming Dot Org,

Tamale, Ghana

mubarakstateman@yahoo.com

\author{
Ibrahim Abukari Zukpeni \\ Grooming Dot Org, \\ Tamale, Ghana \\ zukpeni@yahoo.com
}

Sulemana Abu

Tamale Youth Home Cultural Group,

Tamale, Ghana

abuflute@yahoo.com

Received: June 2, 2016 / Accepted: September 12, 2016 / Published: December 16, 2016

\begin{abstract}
Music is a social technology of enormous potential for improving community health. This paper reports on a series of applied ethnomusicological interventions, enacted as a participatory action research project in northern Ghana, for health promotion. Initial interventions, performed by local professional urban artists, proved effective. But as they were not sustainable, we followed up by training village-based amateur youth groups, rooted in the local community, to perform a similar repertoire. These methods can be transposed to other societies maintaining participatory musical traditions, leading to improved community health whenever
\end{abstract}


behavior is a primary determinant, as is so often the case (WHO 2002).

Keywords: edutainment, Participatory Action Research (PAR), sanitation, malaria, Ghana

Music - along with allied performing arts such as dance and drama - is a social technology of enormous potential for community health, and one that can be harnessed through participatory action research ethnomusicology. Moving beyond the usual scholarly goals of interpretive or empirical understanding, such an ethnomusicology leads to a series of collaborative, non-clinical musical interventions, each designed to produce positive community health outcomes through awareness, social cohesion, and behavioural change, along with impact assessments providing guidance for the next one. This paper reports on a series of such interventions for health promotion, enacted as an on-going project entitled "Singing and Dancing for Health" in northern Ghana.

\section{Theoretical Reflections on Traditional Music for Health Promotion The importance of Health Promotion}

An ounce of prevention is worth a pound of cure - nowhere is this truer than in matters of health. Some aspects of the health system require significant investment in infrastructure and personnel - hospitals, staffed by health professionals, or MRI scanners. But many public health issues can be addressed preventively through behavioral changes that are entirely within reach of the individual. Prevention is nearly always more economical and more effective, fending off costly illnesses through lifestyle often requiring no significant expenditures.

How to effect such changes? What is required is effective communication of health knowledge that translates into action, i.e. not simply conveying information, but conditioning a shift in collective attitudes, a social change enabling a corresponding shift in individual behaviour. Supporting such a shift towards healthier lifestyles, known as "health promotion" (Bunton \& Macdonald, 2002; Corcoran, 2007; WHO, 2016), depends in part on health education. But disseminating such knowledge to individuals, though necessary, is insufficient in itself; information can only support better health when it generates healthier behaviours, which are also likely conditioned by broader social factors that must simultaneously be addressed.

In the developed world, essential behavioral modifications center on lifestyle changes such as better nutrition, less alcohol, no tobacco, and more exercise to prevent chronic conditions such as heart disease, cancer, lung diseases, and diabetes. By contrast in a developing country such as Ghana serious health problems stem more from basic environmental issues, such as poor sanitation, leading to infectious diseases, pre-eminently malaria, lung, and diarrheal diseases, especially cholera. Here, prevention is crucial to a precarious health system. As Glanz, Rimer, and Viswanath note:

In many parts of the world, infectious diseases continue to pose grim threats, especially for the very young, the old, and those with compromised immune systems. Malaria, diarrheal diseases, and other infectious diseases, in addition to AIDS, are major health threats to the poorest people around the world ... like chronic diseases, their trajectory may be influenced by the application of effective health behavior interventions. Substantial suffering, premature mortality, and medical costs can be avoided by positive changes in behavior at multiple levels. $(2008$, p. 6) 


\section{Communication for Development, and Traditional Music as Development Technology in Africa}

The crucial role of communication for development has been increasingly recognized in recent decades (Ansu-Kyeremeh, 2005; Ford, Williams, Renshaw, \& Nkum, 2005; Asante, 2004; Pratt, Silva-Barbeau, \& Pratt, 1997; Moemeka, 1994). Clearly, such communication is crucial for preventive medicine requiring behavioral change. But what sort of communication is required, particularly in rural Africa, where the rate of illiteracy is high, and media presence is limited? Knowledge must be transmitted in a form that engages community, so as to inform the individual but also to transform the larger social group.

The keys to community engagement, therefore, are communicative forms that enable active, grassroots participation: forms that are familiar, affective, and social. Towards this end, print material has limited value, particularly with low literacy, and even audio-visual messaging carried through mass media - radio, TV, or billboard - though reaching large numbers of people quickly, may be ineffective because such media are received passively and asocially. They raise awareness but often without the accompanying social transformations required to produce action. As Macdonald remarks in a summary article on communication theory and health promotion, "mass media serve to inform and raise awareness admirably but they have limited effect in changing opinions or behaviour" (2002, p. 205). Several empirical studies confirm this limitation, e.g. Wimbush, MacGregor \& Fraser (1998) on the impact of a mass media campaign to promote walking in Scotland. Furthermore, mass media channels (radio, TV) - while attractive - may be perceived by rural residents as alien.

Mass-mediated health campaigns carrying local expressive cultural forms enjoy considerable popularity, especially in urban zones (Frishkopf, 2017; Frishkopf and Morgan, 2013a \& 2013b; more globally, see the work of the Vermont-based Population Media Center). But mediated forms lack the affective immediacy, social force and adaptive flexibility of interpersonal oral communications transmitted via face-to-face social presence. This modality becomes both more important and more effective in rural zones, where the entire village effectively functions as a single, coordinated, cohesive "community of practice", a "group created over time by the sustained pursuit of a shared enterprise" (Wenger, 1998, p. 45) bound by mutual engagements, shared cultural practices, and common social commitments. This feature of the rural community is in contradistinction to the urban zone where a larger, more diverse population and the consequent division of labour preclude such unity (Barlocco, 2010; Durkheim, 1964).

Writing about southern Africa, media scholar Ocholla (2006, p. 2) identifies three conditions as marking "information poor" communities in southern Africa: economic disadvantage; geographical isolation; and illiteracy; rural northern Ghana exhibits all three. Ocholla goes on to observe that

Although information can be accessed textually, electronically, visually, audibly and orally, most information poor communities prefer information orally and such information should be provided closest to them by sources familiar to them such as colleagues, neighbors, relatives and friends as attested in most studies. The conception of knowledge sharing through "community of practice" works fairly well in this environment. (Ocholla, 2006, pp. 3-4) 
There are many ways to achieve such face-to-face presence in communication for development. Some researchers have explored the use of adult education classes for public health education, relying on diffusion through sharing information with friends and family to expand the scope of impact beyond the classroom (Freedman, Miner, Echt, Parker, \& Cooper, 2011). However, such an approach is relatively expensive; diffusion is limited by class size; and the classroom approach presumes availability of time and inclination for adult education, which is not typically a culturally local channel.

The importance of community-engaged diffusion of health information through local communication channels has been widely recognized as appropriate to rural African settings. However, such methods of education, on the one hand suffer from comparatively low literacy and media access, and yet, on the other, also benefit from much greater community cohesion, as compared to urban areas or the West, affording opportunities that may not be available in urban areas (Ford et al., 2005).

What appears to be required, then, is a form of information diffusion that is at once "mass", "face-to-face", and local. It should be affective, culturally engaging, interpersonal, and intergenerational, productive of affective social relationships while flowing through existing ones. Traditional music culture fills this bill. A catchy song in traditional style, building on traditional proverbs and introduced into the midst of a festival context, gathers a live audience of hundreds of participants; its messaging is far more powerful and memorable due to face-toface communication in a context of communal focus, recognition, and approval. Contemporary popular mediated forms (e.g. hip-hop, or "hiplife" in Ghana) are undoubtedly important to the youth - as evidenced in the success of "Sanitation" (Frishkopf \& Morgan, 2013ab). However, traditional music is live and multigenerational, and thus capable of nucleating broad social gatherings, sustaining, and forging powerful bonds infused with musical content, including health messaging, that connects one generation to the next. Furthermore, unlike mediated forms, live music can dynamically adapt to context, as each village - even each context - presents unique requirements and offers unique opportunities.

Oral expressive culture, including music, song, dance, drama and storytelling - collectively labelled "oraculture" by Ugboajah (1985) - are particularly important for communitybased communications in sub-Saharan Africa, as demonstrated, for instance, in a study on nutrition communications (Pratt, Silva-Barbeau, \& Pratt, 1997). Others have also noted the importance of harnessing traditional modes of communication in Africa (Osho, 2011; AnsuKyeremeh, 2005; Asante, 2004).

While "low tech", interpersonal oraculture also possesses an inherent mass power beyond the context of performance, through its potentially exponential rates of "word of mouth" diffusion, as receiver becomes, in turn, transmitter, to the boundaries of the sociocultural community. A mediated version of such diffusion had to await the cassette era (before which copying media was hardly feasible), but face-to-face culture had always enabled it, especially via songs, which are easily remembered, relayed from one person or community to the next, passed synchronically onwards in geometrical progression, as well as, diachronically through successive generations, ultimately absorbed into the durable oral tradition. "Viral" culture diffusing rapidly through social networks did not emerge with online social media; it is an age-old phenomenon in pre-technological social networks as well, through live face-to-face or "word of mouth" performances.

Community-based diffusion through face-to-face networks, while slower than mass mediation, is also a more trusted form of communication. Even in our post-modern, media-rich, Internet-based society, information received through face-to-face interactions is considered our 
most reliable source, most persuasive and conducive to diffusion. Behavior change research that weighs mediated against interpersonal diffusion acknowledges this as well (Nielsen, 2013, p. 2; McAlister, 1991; Rogers, 1983, p. 18).

Further, such dissemination, unlike the rapid decay of contemporary mediated "memes", diffuses more durably in two dimensions, one spatial-social (synchronic), and the other temporal-social (diachronic), thanks to two key properties of oral transmission: (1) information receiver becomes information sender, enabling diffusion through interpersonal communication; (2) supporting each act of interpersonal communication is a prior social relationship, which is subsequently strengthened. Diffusion transpires synchronically, through a social network representing a contemporary community, and diachronically, from one generation to its descendants. The former modality potentially transpires with exponential speed at least to the boundaries of the social network, while the latter ensures sustainability over time. Both serve to strengthen social cohesion.

Diffusion is no doubt enhanced by encoding a message as poetry, and then setting the poem to music as song, increasing its appeal and memorability, as music and poetry serve a mnemonic function in many cultures (Rainey \& Larsen, 2002). Thus, music can function as a powerful mode of dissemination for public health information even - or perhaps especially in the absence of electricity and its attendant gadgetry, and a fortiori in rural societies where traditions are more familiar and social groups smaller and more cohesive.

The power of traditional music as a social technology for health promotion stems from the fact that music acts on three levels simultaneously: cognitive communication of information (so-called "communication for development", in this case health education); affective reinforcement through traditional music's cultural resonance and authority; and the resulting galvanizing of intergenerational social groups, face-to-face communities of practice centred on music. Musical messaging, centered on an imperative for behavior change, supports better health primarily through "prevention" rather than "cure", and through everyday behavioral changes effected via individual choice, rather than social or technological interventions from the health establishment.

Music for health promotion has a long history within "edutainment"; many of its uses have been enumerated in Barz and Cohen's edited collection; documenting how African expressive arts "gained prominence as agents for addressing HIV and AIDS," including case studies from many African countries (Barz \& Cohen, 2011; Barz, 2006). These studies show that much musical AIDS education has centered on popular music disseminated through the mass media, but there are also many instances of more traditional community-based music-making performed live.

While it enjoys large support among musicians and ethnomusicologists, on the whole that is, within the field of health promotion at large - traditional music is insufficiently recognized and operationalized as a powerful and economical social technology for community health promotion in Africa.

Such an approach can be particularly effective in rural areas, where such music - performed live on traditional and civic holidays - still enjoys broad, multigenerational popularity. Unlike in the West, or even in urban Africa, the community of musical practice in villages is typically the entire village, even if everyone does not participate in exactly the same way, because the village social network is dense and the culture relatively homogeneous. Our initial interventions were exogenous - dance drama performances created by professionals in Accra and Tamale; while there was a certain level of village participation (we invited local groups to perform; local "opinion leaders" made speeches), the primary village role was as spectator. 
Being formulated in the local language and musical style and presented live in a traditional setting, the performances were familiar and deeply engaging. But they were viewed - at least in part - as coming from outside. We nevertheless selected this approach to ensure quality, impact, and conformity to budgets and timelines.

But we hypothesize that once such an intervention is "adopted" by the villagers themselves, through an expansion of the collaboration to include villagers as active participants, the intervention can be absorbed into the social fabric and its associated oral tradition to become community-based. Reproduced through oral tradition, it enters the community of practice, and becomes a sustainable cultural form of great power for non-clinical community based preventive medicine (National Academy of Sciences, 2012, p. 23). In short, the propagation of health information over a performing arts substrate takes advantage of the status of traditional live music as a participatory "community of practice", in which everyone plays a role. Here, performance and social structure are mutually reinforcing, as music tightens and rejuvenates social bonds, bonds which themselves serve as conduits for music-based health information.

\section{The Dance Drama, and Health Promotion}

So long as the musical genre is sufficiently flexible any traditional style can be adapted for health promotion by suitably modifying lyrics, or placing music in a context where healthpromotion meanings are established, such as a larger multi-art performance event, one sustaining attention and engaging all the senses, communicating in parallel through music, song, dance, gesture, costume, and narrative drama. Obviously, some measure of flexibility is crucial here; in particular, sacred repertoires, genres, and ceremonies, whose contents have been sacralised through long usage and connection to sacred or secular authorities (e.g. divinities, chiefs) do not lend themselves to adaptation. However, there are other forms - often modern "recreational" types - that do allow for such creative play. While such forms have sometimes fallen into disuse under the influence of modernity, they can be revived when endowed with a contemporary social role, meaning, and purpose.

In Ghana one such contemporary form is the dance drama, a light entertainment nonparticipatory genre, drawing on Ghana's long-standing story-telling tradition, perhaps influenced by the popular 'concert party' (Cole, 2001), and by government-sponsored ensembles formed post-independence to celebrate local culture in a staged setting, such as the Ghana Dance Ensemble under director Francis Nii-Yartey, disseminated via mass media (Schramm, 2000, p. 347). The dance drama is a compound form whose rich weave of music, lyrics, dance, narrative, humor and costume, completely open to creative interpretation, can powerfully focus social attention on key issues, such as the necessity of adopting specific healthy behaviours, and rejecting unhealthy ones, while quickly gathering a large audience through its familiar multisensory aesthetic force. Dance dramas are bound together by traditional music (and dance) which serves as an affective and highly meaningful substrate for the transmission of health information in an intensive social setting. Presented in this way, memorable health messaging reaches a wide audience with the power to alter behavior and promote better health.

The power of traditional music reconfigured within the dance drama context inheres in its ability to gather and move multiple generations at a socio-affective level. In this way, health promotion messages diffuse as more than simply informational; rather they are memorably wrapped in an aura of traditional musical content, verbal style, identity and authority, reinforced by the witnessing presence of the full community, particularly with the support and attendance 
of opinion leaders, such as chiefs, imams, elected officials, Ghana Health Service representatives, and other notables, whose official blessing is underscored through eloquent public statements. With the force of such authority, messages are thus infused into the social fabric, instilled through a performative setting of affective communality that typifies such public performance occasions. Meanwhile the social fabric itself is transformed and strengthened, particularly along its vertical inter-generational dimension, helping reverse the social anomie that has so often accompanied rapid social and economic change in rural areas (and is often accompanied by a decline in traditional music making). Social cohesion is in itself a key resource for promoting better health (Wilkinson, 1997; Kawachi \& Kennedy, 1997; Kawachi, Kennedy, Lochner, \& Prothrow-Stith, 1997).

\section{Social Background: Northern Region and the Dagomba}

Judging by its population and scarcity of resources, Ghana's Northern Region appears among the least well-served by the country's national health system. With a population of $2,479,461$ according to the last census, the Northern Region is Ghana's fourth most populous, yet its literacy rate of $37.2 \%$ is the lowest across all ten regions (Ghana Statistical Service, 2012, pp. $22 \& 41)$. The region is the third most rural (69.7\%) with the lowest population density $\left(35.2 / \mathrm{km}^{2}\right)$. Electronic media play a limited role; only $0.86 \%$ of rural households contain a computer and rural internet usage is just $0.78 \%$; only $12 \%$ of rural residents own a mobile phone. These are the lowest regional rates in Ghana. Here, one also finds the lowest number of health professionals per capita (Ghana Health Service, 2010, p. 16; Ghana Statistical Service, 2012, p. 21). These facts suggest that live traditional performance should be especially useful for dissemination of health information in rural northern Ghana.

As dance dramas center on language and music, and we did not wish to deal with the additional complications of translations and multilingual performers, we needed to select just one ethnic-linguistic group. We therefore picked Dagbani, the language spoken by the Northern Region's majority ethnic group, the Dagomba, who traditionally inhabit the kingdom of Dagbon. Ghana's Dagbani speakers number about 1.1 million (Dagbani, 2016). Dagbani is also the primary language of our artistic collaborators, Youth Home Cultural Group, a well-established NGO based in Tamale.

The traditional lands of the Dagomba, extending from just west of Tamale to Togo, are savannah; malaria is endemic, and sanitation problems are rampant. In order to leave open the possibility of comparison from as many angles as possible we selected three contrasting Dagomba villages across this zone: Tolon (a district capital of about 4000); Ziong (a smaller town); and Gbungbaliga (the smallest, near Yendi, the traditional capital of Dagbon). A fourth village, Jekeriyili, lying within greater Tamale yet exhibiting features of remote rural settlements, served as a convenient yet realistic location for performing and filming each dance drama before a live audience (Figure 1). 


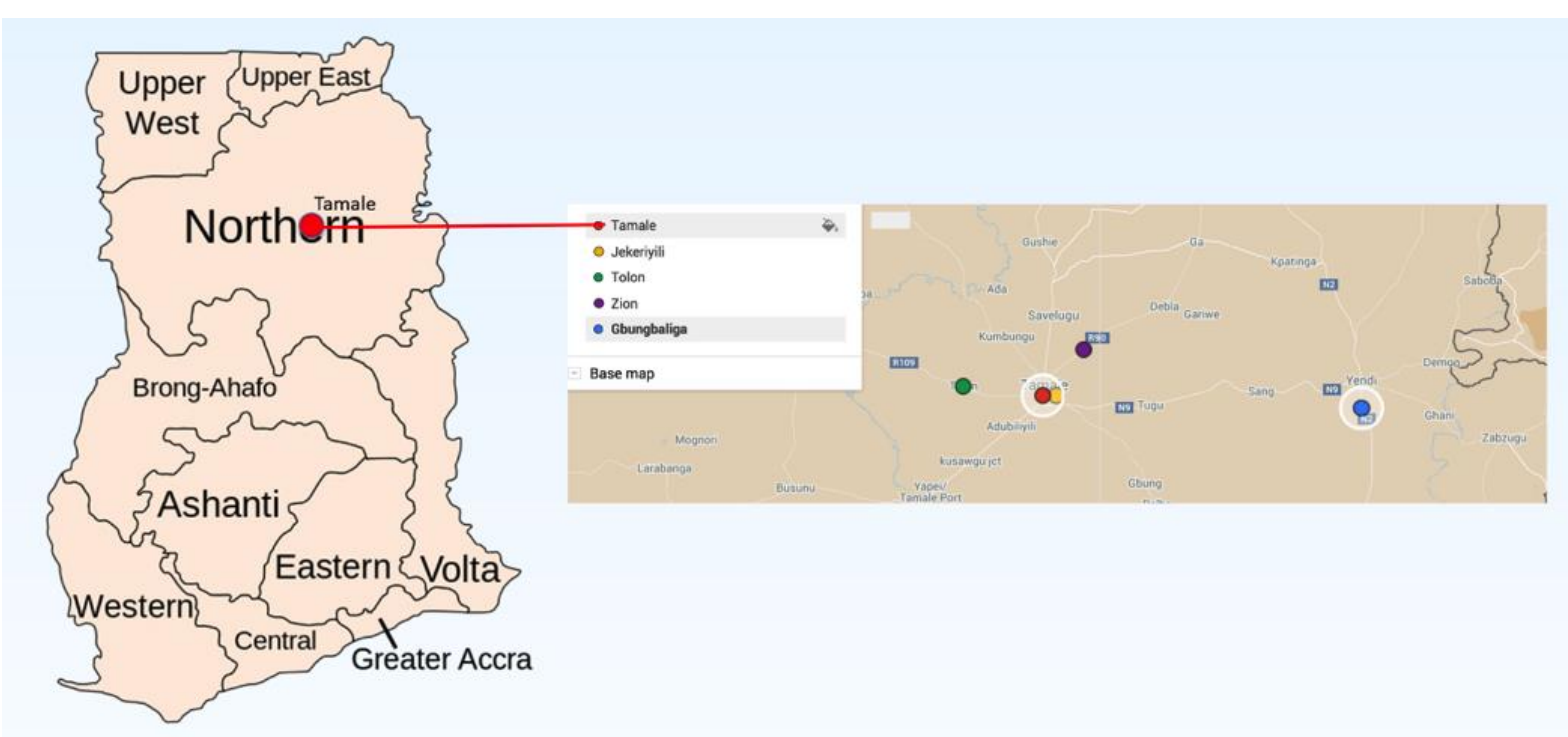

Figure 1: Ghana's ten regions and the locations of research

The Dagombas are celebrated for their elegant performance culture, featuring twirling dancers and interlocking pressure and bass drums. In rural areas, many genres of traditional performance have receded due to poverty and urban migration, except for those attached to the chieftaincy and religious holidays for which music is crucial (MacGaffey, 2013; Corke, 2000; Locke, 1990; Chernoff, 1979; Staniland, 1975; Oppong, 1973; Kinney, 1970). However, this loss is a consequence of socio-economic change, not a desideratum. Local communities welcome the revival of such genres, whether for health promotion or any other purpose.

Modernity brought the dance drama to the Dagombas, via the cities. Visually, acoustically, and dramatically spectacular, and drawing on traditional dance styles, the dance drama easily draws a large audience in the region. While not as participatory as traditional genres such as Damba (Kinney, 1970; Locke, 1990), community participation is potentially open, and the dance drama easily incorporates other musical styles. Its relative novelty enables greater artistic freedom; the dance drama draws on traditional culture without being constrained by it. Mediating tradition and modernity, the dance drama is therefore well-suited for adaptation to development communications, and has often been used in this fashion by our research partners, the Youth Home Cultural Group (YHCG, 2016) in other contexts.

\section{"Singing and Dancing for Health"}

"Singing and Dancing for Health" is a performative public health initiative, a series of Participatory Action Research (PAR) interventions focused on dance dramas combining music, dance, costume, poetry, narrative, melodrama, and comedy - as a social technology for preventive medicine in rural Dagbani-speaking areas of Ghana's Northern Region. Participatory Action Research implies that the initiative was collaborative from the outset. From the point of project formulation, the team - involving researchers, artists, and public health experts from Canada and Ghana - made key decisions together. PAR also implies evaluative research, in the form of impact assessments, as a means of guiding the project through its multiple phases towards greater effectiveness (Figure 2). Initial team discussions revealed that two key health problems addressable through behavior modification are malaria and lack of proper sanitation, and we therefore resolved to develop two dance dramas to focus on each of these. 


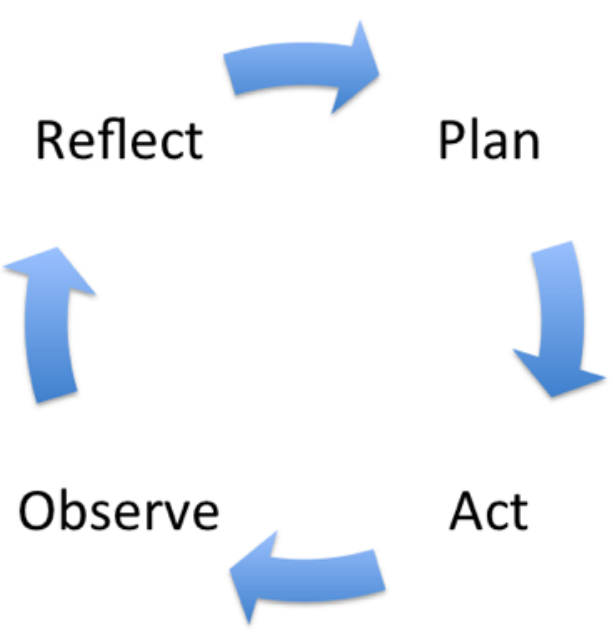

Figure 2: The PAR paradigm - a collaborative, community-engaged research cycle for positive social change (Kemmis \& McTaggart, 2005, p. 276)

The initiative thus far has run through two phases in three villages, representing two different approaches to musical interventions for rural public health. In the first, the core team comprised members from Canada and from the urban area of Tamale; key village residents the chief, elders, imams, elected officials, teachers, and representatives of Ghana Health Service - were also involved in order to enhance uptake, acceptance, and diffusion (Puska et al., 1986). Evaluative research showed this approach, centering on performative interventions by professional artists guided by music and health researchers, to be effective. However, these interventions proved unsustainable and socially disengaged, due to their exogenous nature and on-going expense. Using outside professionals meant that performances were costly, and recurring costs could not be sustained. Further, impact was limited because performance was socially extrinsic to the rural community of practice, even if content resonated strongly with local musical and community life.

In the second phase, we expanded the core team to include village youth - supported by teachers and parents - as active participants. This time, we deployed the external team's professional artists and craftspeople; not to perform, but to convene, equip, and train local groups. This phase thus centered initially on pedagogical interventions resulting in the formation of youth groups capable of rehearsing and performing the new health repertoire independently on school, civic, and traditional holidays. These endogenous groups are in principle sustainable; as amateurs, members do not require payment. Rather, participation is its own reward; they represent a community caring for itself. Though the outcome of this phase will take time to assess, we anticipate that these groups will establish a new strand in the local oral tradition, and will also serve to strengthen local social cohesion through intergenerational involvement.

\section{Methods}

We applied a Participatory Action Research (PAR) paradigm (Fals-Borda, 2005), forming a collaborative, multinational core team to set the research agenda, carry it out, assess and analyze evidential data, both quantitative and qualitative. This team included a variety of participants: Canadian university researchers (engaged in ethnomusicology, global health, public health, medicine), Ghanaian researchers (in community health, family medicine, communica- 
tion), Ghanaian writers and artists (scriptwriters, choreographers, actors, musicians, and dancers, in Tamale and Accra), Ghana Health Service officers (in the three research villages), and local opinion leaders in the communities where we worked. ${ }^{1}$

The boundaries of participation are deliberately fuzzy and open in PAR, and the broader team included also local opinion leaders (chief, elders, imams, teachers, elected officials), Ghana Health Service, traditional village music groups (who performed prior to our intervention), subjects for surveys and focus groups, and the audience, taking an active role in watching and responding to performances.

Members of the core team included the following groups, individuals, and roles. The performing group was largely drawn from the Youth Home Cultural Group (YHCG, 2016), a Tamale NGO founded in 1985, augmented by two professional comedic actors. Besides training performers, YHCG also includes workshops producing instruments and clothing, and thus was able to supply the village youth groups we established. Four members of YHCG took on special roles: Abdul Fatawu Karim, artistic director, led rehearsals and developed choreographies; Abu Sulemana, project manager, coordinated operations, handled local finances, and assisted with music, data collection, and media production. Alhassan Mohammed Assau and Zakaria Ibrahim served as trainers in dancing and drumming, respectively. Two local researchers, Mubarak Alhassan, and Ibrahim Zukpeni, helped develop, administer, and code the survey, and also assisted in audio-visual documentation.

In Canada, David Zakus, Professor of Distinction in Global Health at Ryerson University, served as global health advisor and guided the project's scientific dimensions. His research assistant, Hasan Hamze MPH, conducted statistical analyses of the survey data. Michael Frishkopf, Professor of Ethnomusicology at the University of Alberta, developed the initial concept, sought and obtained funding, and worked closely with Ghanaian partners throughout the project.

\section{Phase I}

\section{Overview}

In the first phase, described in greater detail elsewhere (Frishkopf, Hamze, Alhassan, Zukpeni, Abu, \& Zakus, 2016), our central concern was to design dance dramas to combat malaria and cholera, by manipulating the art form's aesthetic elements to gather a community audience and transfer key health messaging, redundantly through multiple registers (cognitive, emotional, and social), relevant to knowledge, attitudes, and behaviors that might help reduce the incidence of these endemic diseases.

We developed two such dance dramas addressing two key health issues: malaria and sanitation/diarrheal diseases, for performance in three rural Dagomba villages. Performed together in an afternoon, the power of performance drew each village out and together, enabling health messaging to be widely diffused (cf. Weare, 2002). Knowing that local participation is crucial to acceptance, we worked collaboratively with opinion leaders and Ghana Health Service in each locale. Doing so helped guide the project effectively, and ensured positive receptivity and uptake. Statistical analysis of impact assessments (surveys, tracking, focus groups, testimonials) indicated effectiveness (Frishkopf, Abu, Mubarak, Zukpeni, Hamze, \& Zakus, 2016).

\footnotetext{
${ }^{1}$ While we subsequently learned of a number of Ghanaian theater for development projects (e.g. Centre for Popular Education and Human Rights, and the Agoro Project in Cape Coast), we were not aware of them at the time we formulated this.
} 
Our hypothesis was that the impact of such interventions would prove measurably effective in raising awareness, changing attitudes, and inculcating healthier behaviors. This impact would first affect those in attendance, and our aim was to maximize that number (to the capacity of the performance space), but also would subsequently diffuse - through social networks defined by family, friend, and work connections - to other, non-attending villagers as well. The fundamental method was therefore simple: develop the dance dramas (scripting, composing, choreographing); rehearse and refine them; publicly perform, film, and subtitle them (thereby testing the method, while generating a media version for future presentation and possible broadcast); conduct pre-intervention surveys; perform and observe the intervention; conduct post-intervention surveys; and analyse resulting data.

\section{Timeline}

Frishkopf first met members of YHCG in 2008, when he brought his summer students to study with the group in Tamale; such visits continued annually through 2010, and recurred in 2013. In January 2014, he returned to Tamale to conduct ethnomusicological research on the Prophet's Birthday festival (Damba), with support from members of YHCG. In light of recent collaboration with Liberian artists resulting in a music video and documentary addressing sanitation issues in urban Monrovia (Frishkopf \& Morgan, 2013a \& 2013b; Frishkopf, forthcoming), he initiated discussions with YHCG on how music could help address the most urgent health issues facing the rural Northern Region. In contrast to Monrovia, the consensus was that live rather than mediated music would be more successful, as well as more appropriate for YHCG, and that malaria and sanitation should be prioritized as most critical to public health.

At the end of that month he returned to Canada, and - collaborating with David Zakus - succeeded to obtain funding from the Killam Foundation the following May, with contributions also from the University of Alberta's Faculty of Arts, Faculty of Medicine and Dentistry, and Canada's DFATD (Department of Foreign Affairs, Trade, and Development).

Guided by YHCG's Sulemana Abu the team expanded to include additional team members: videographers, researchers (Alhassan and Zukpeni), and an Accra-based writer. The latter developed dramatic scripts in English, centered on the two health issues these were vetted and edited by Zakus and Frishkopf for scientific accuracy and narrative flow. YHCG then translated the scripts into Dagbani and infused them with artistic life - songs, choreography and costumes - shaped by traditional performance styles. Rehearsals continued throughout the summer. Grant money purchased needed supplies and equipment, including a laptop, camera, audio recorder, and portable stage and printed banners, posters, and t-shirts.

That September, we mounted performances in Jekeriyili, a village within greater Tamale, a natural setting for filming; footage was edited and subtitled for mass dissemination (available at http://bit.ly/sngdnc4h).

We also developed a list of potential village research sites, narrowing it to three: Tolon, Ziong and Gbungbaliga (see Figure 1). The Ghanaian team visited each village, applying community entry strategies in order to gain local cooperation by explaining the project and its benefits to opinion leaders - chiefs, elders, religious leaders, teachers, elected officials and Ghana Health Service officers - and performing traditional cultural protocols. We photographed each village, considered possible sites for performances, and distributed posters (Figure 3). These strategies also served to publicize the coming intervention. 


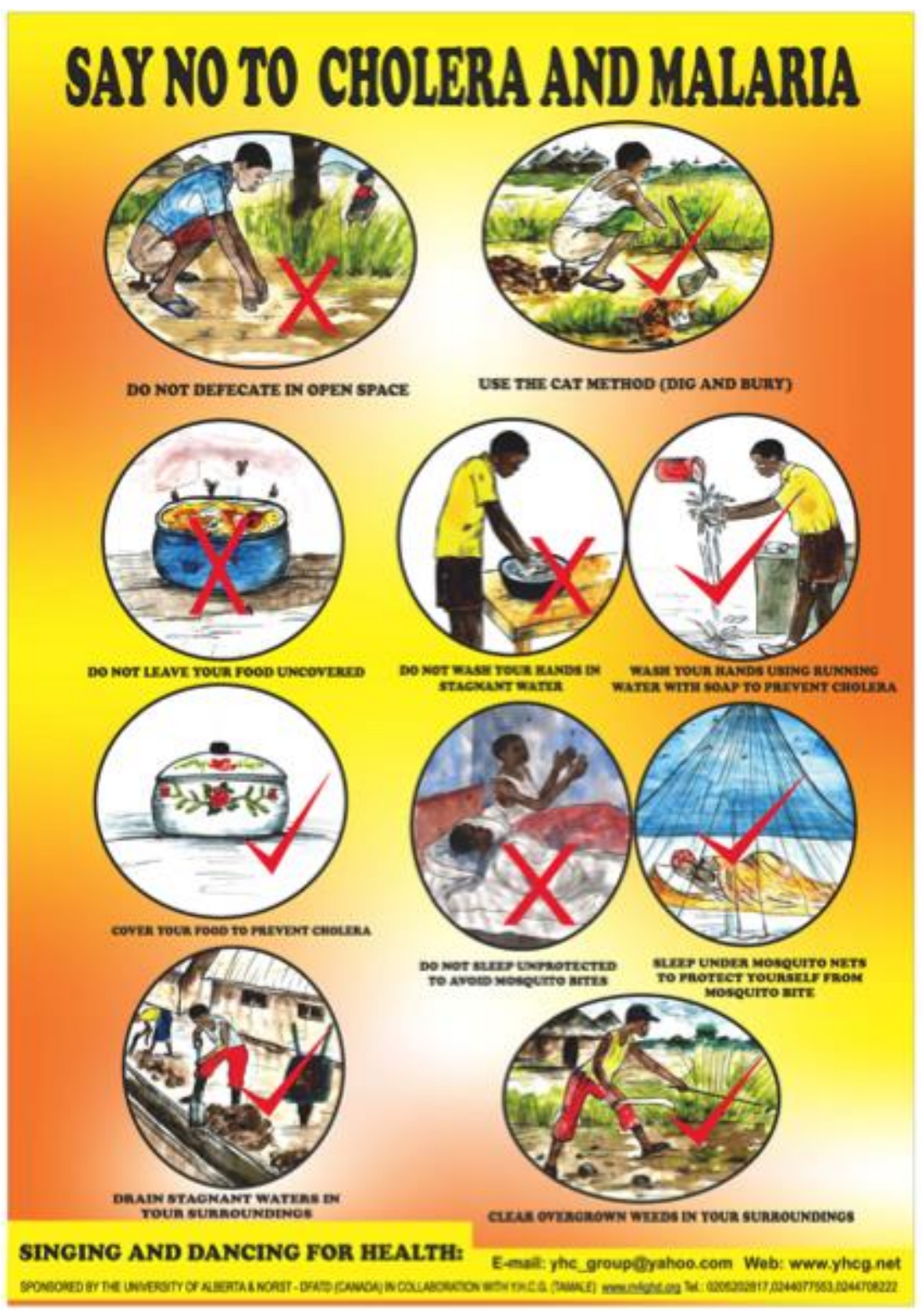

Figure 3: Poster for "Singing and Dancing for Health"

Meanwhile, we developed an elaborate Knowledge, Attitudes, and Practices (KAP) survey instrument (Warwick, 1983; WHO, 2008), which was vetted by statistical and survey research experts in Canada, and subsequently refined, translated and tested by the Ghanaian team. We carried out pre-intervention survey research in November 2014, sampling each adult village population at random for a total of 80 surveys per village, over the course of three days (each survey required nearly an hour to administer), attempting to obtain a random sample by soliciting interviewees at a number of places (school, market, homes, street) and varying times of day (Figure 4). 


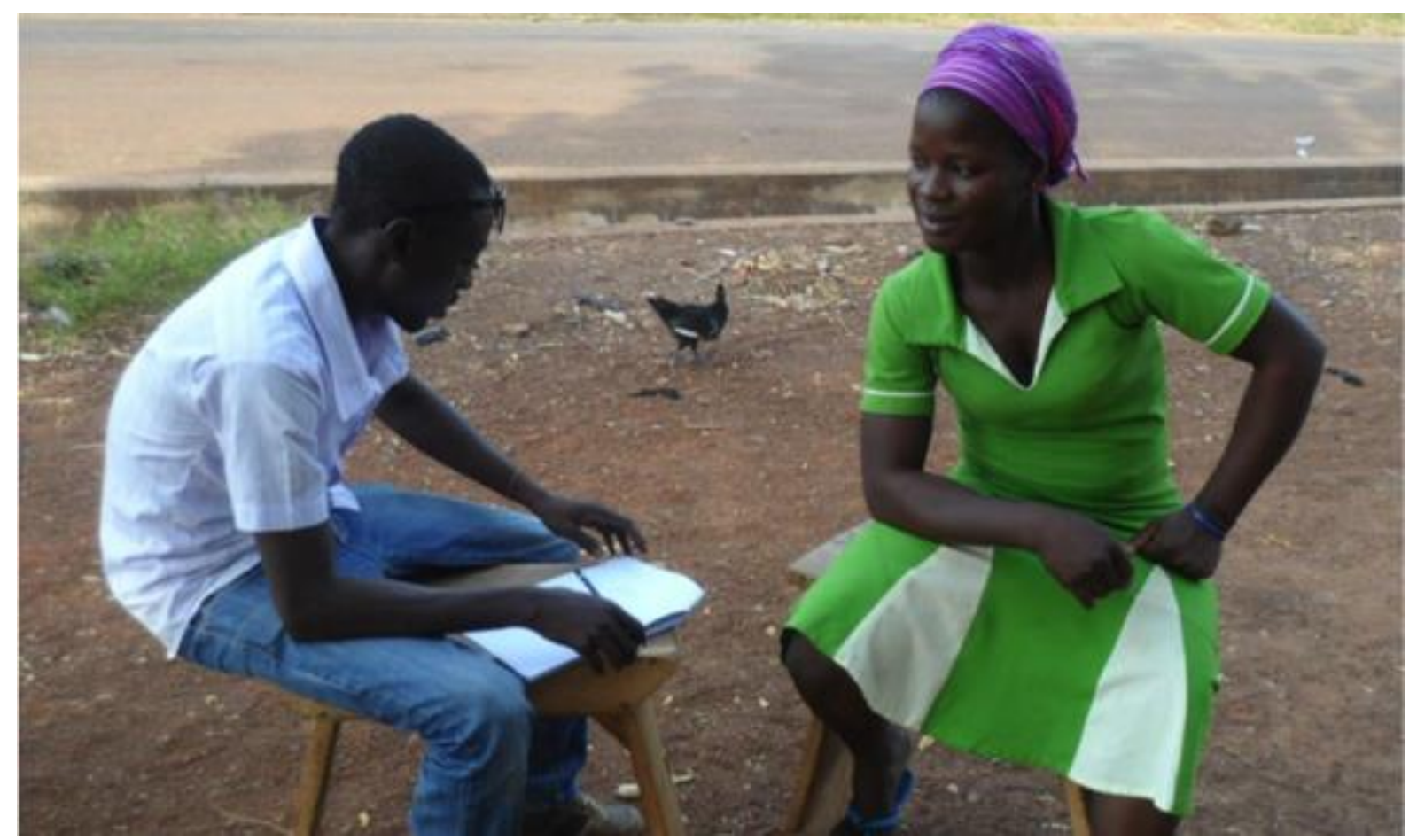

Figure 4: Surveying

Next, we performed the interventions themselves in December of the same year in the three villages, comprising one full afternoon in each village. Arriving in the morning, we set up the stage and sound system, strung up our banners and put up additional posters, thereby attracting attention. By early afternoon we were ready to begin. A parade of drummers and clowns through the village served to draw an enormous crowd to the performance ground (Figure 5). A DJ played popular music at high volume to attract more onlookers, and we opened each performance with a local village music-dance group. This was a strategy to integrate local performers into the project and connect with the communities through artistic exchange. There followed speeches from the opinion leaders we had contacted - the chiefs, imams, Ghana Health Service representatives, and elected officials - emphasizing the importance of the project. Our international team, including leading members of YHCG, gave short speeches as well. The two dance dramas (malaria and sanitation) were then presented in sequence (Figure 6). Each drama combined music and dance with dramatic narrative and comedy that kept the large audiences (an estimated 400 at each performance) focused, and often in stitches (Figure 7). 


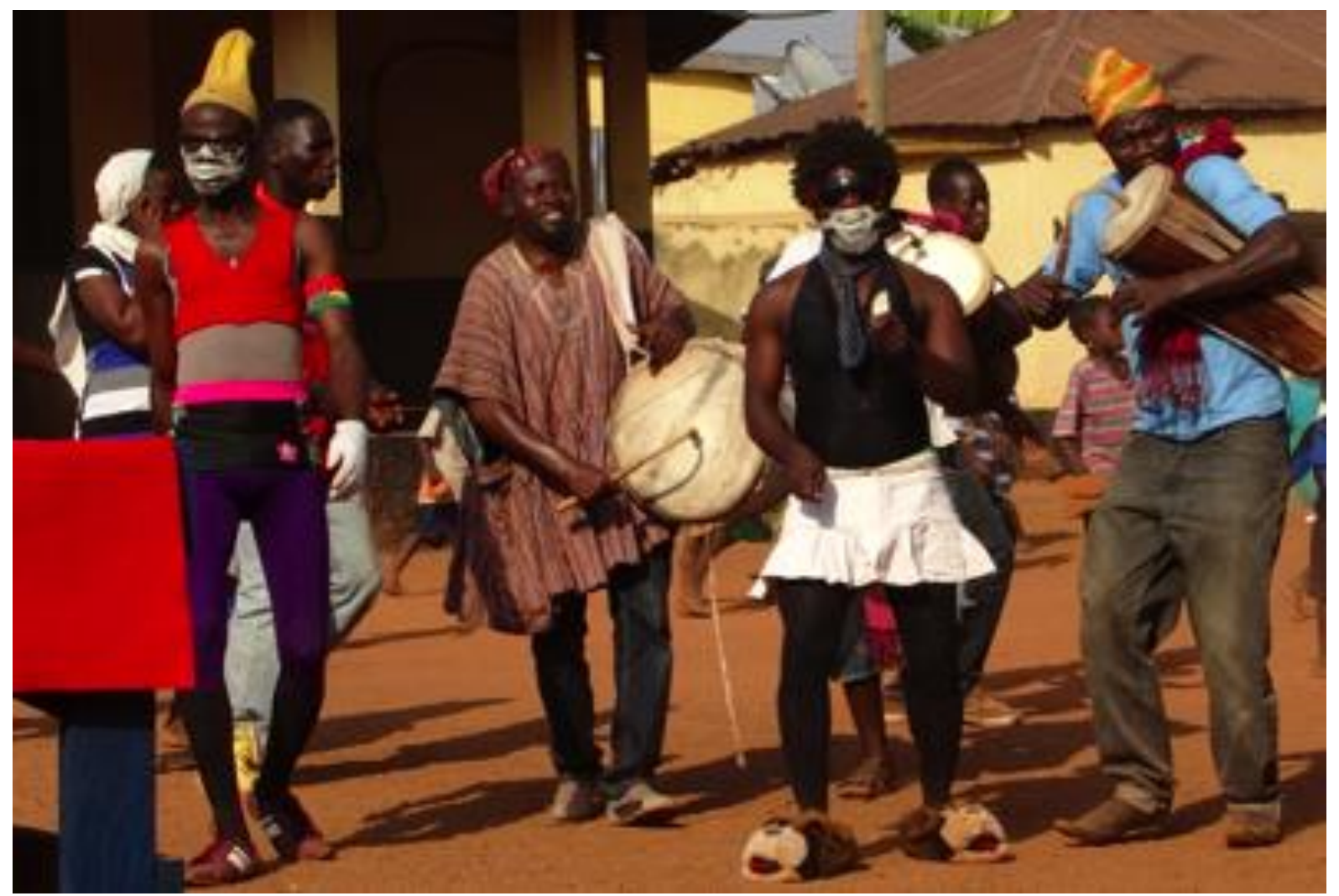

Figure 5: Clowns parade with drummers to gather a crowd

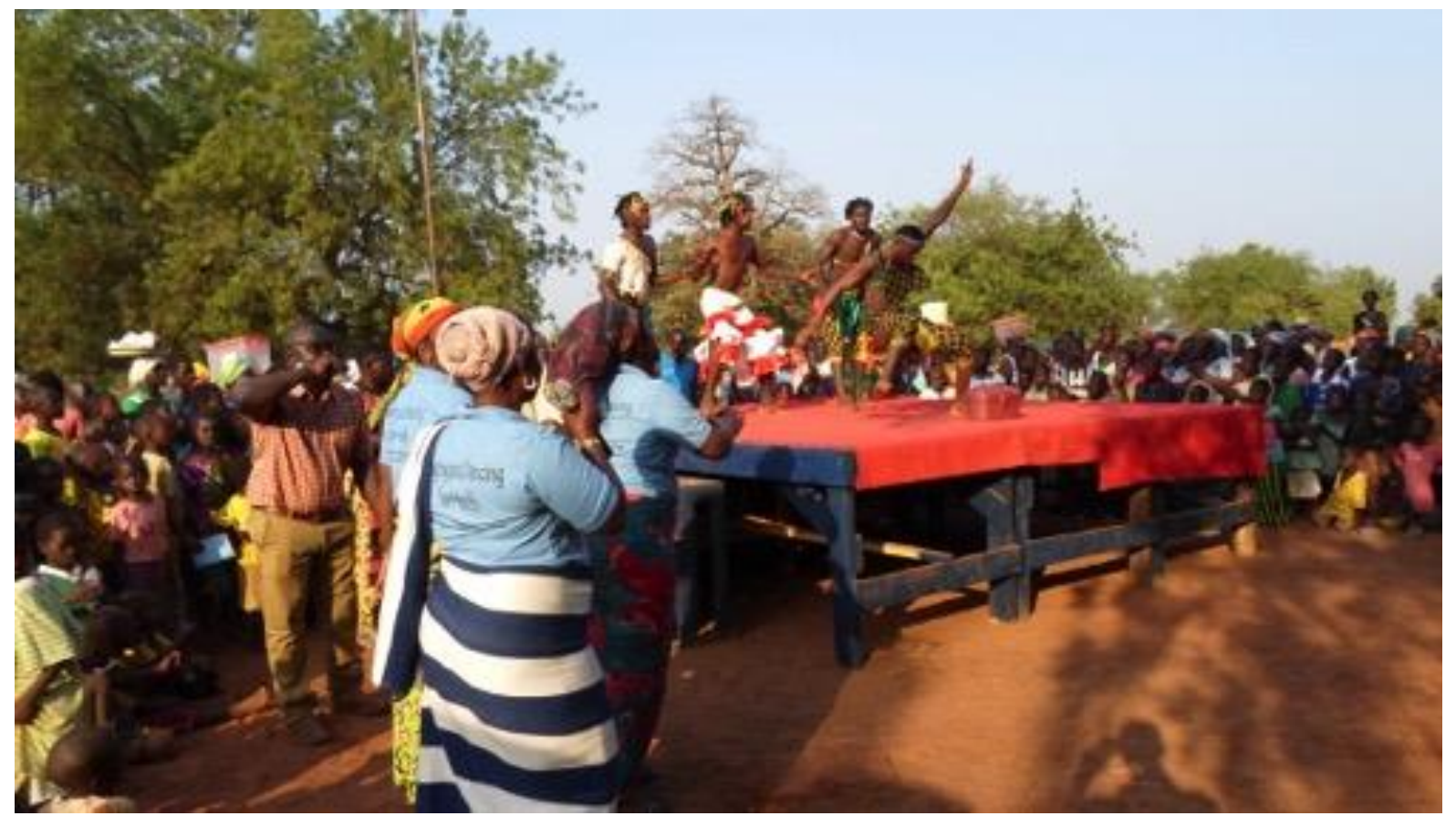

Figure 6: Dance drama performance in Ziong 


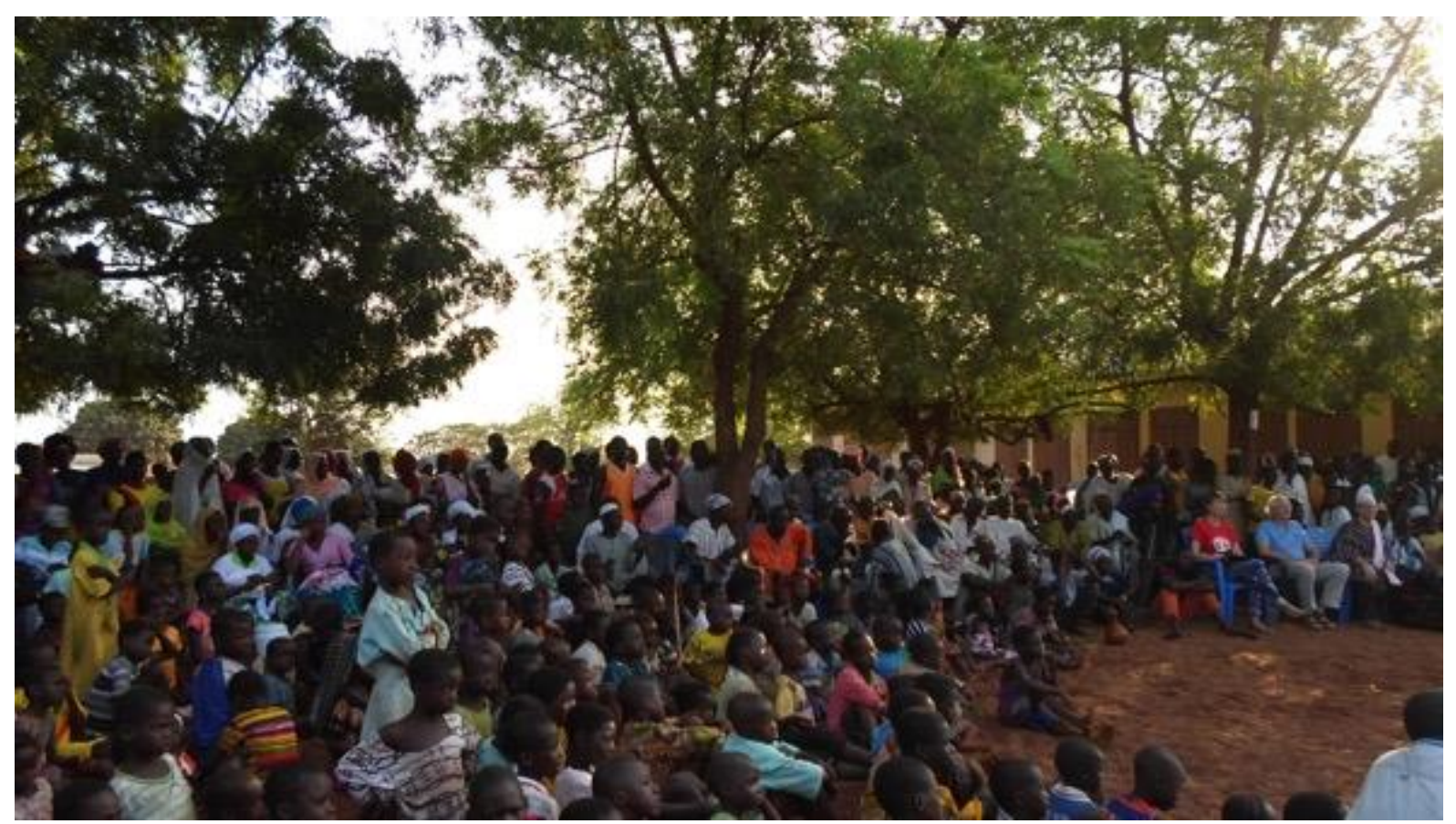

Figure 7: Attentive audience in Ziong; Zakus and Frishkopf visible at right.

The two professional comedic actors adeptly stirred the crowd through humorous antics, costumes, and gestures (as it turned out they were local celebrities, well-known through video films shown in local cinema houses). The audience also appreciated the skilful music and dancing displays combining traditional Dagomba dances with health-oriented gestures and lyrics. Many of these dances, though traditional, are no longer actively performed in Dagomba villages. Thus, for an afternoon these professional artists injected dazzling aesthetic color to the humdrum struggles of ordinary rural life, for which residents appeared most grateful. The performances were highly appreciated by all.

After the interventions, we carried out follow-up research until March 2015, using four methods:

Focus Groups. During the two weeks post performance, we conducted one gender-balanced focus group session at each village site in order to elicit comments from the youth, representing the future of each community, and appearing most likely to have the time and energy necessary to participate (Figure 8). Each group comprised 20 twenty junior high school students. (These groups later served as starting points for the introduction of local drummingdancing groups.)

Tracking. We enlisted 30 articulate and observant volunteers - ten from each village to agree to share their telephone numbers with the core research team, in order to be contacted approximately every two weeks for reports on observed behavioral changes in their homes. Each volunteer provided four short reports. The fundamental question was: "What is your perception of the attitudes and practices of family members in the same household after the intervention?" We also sought suggestions for improvement. 


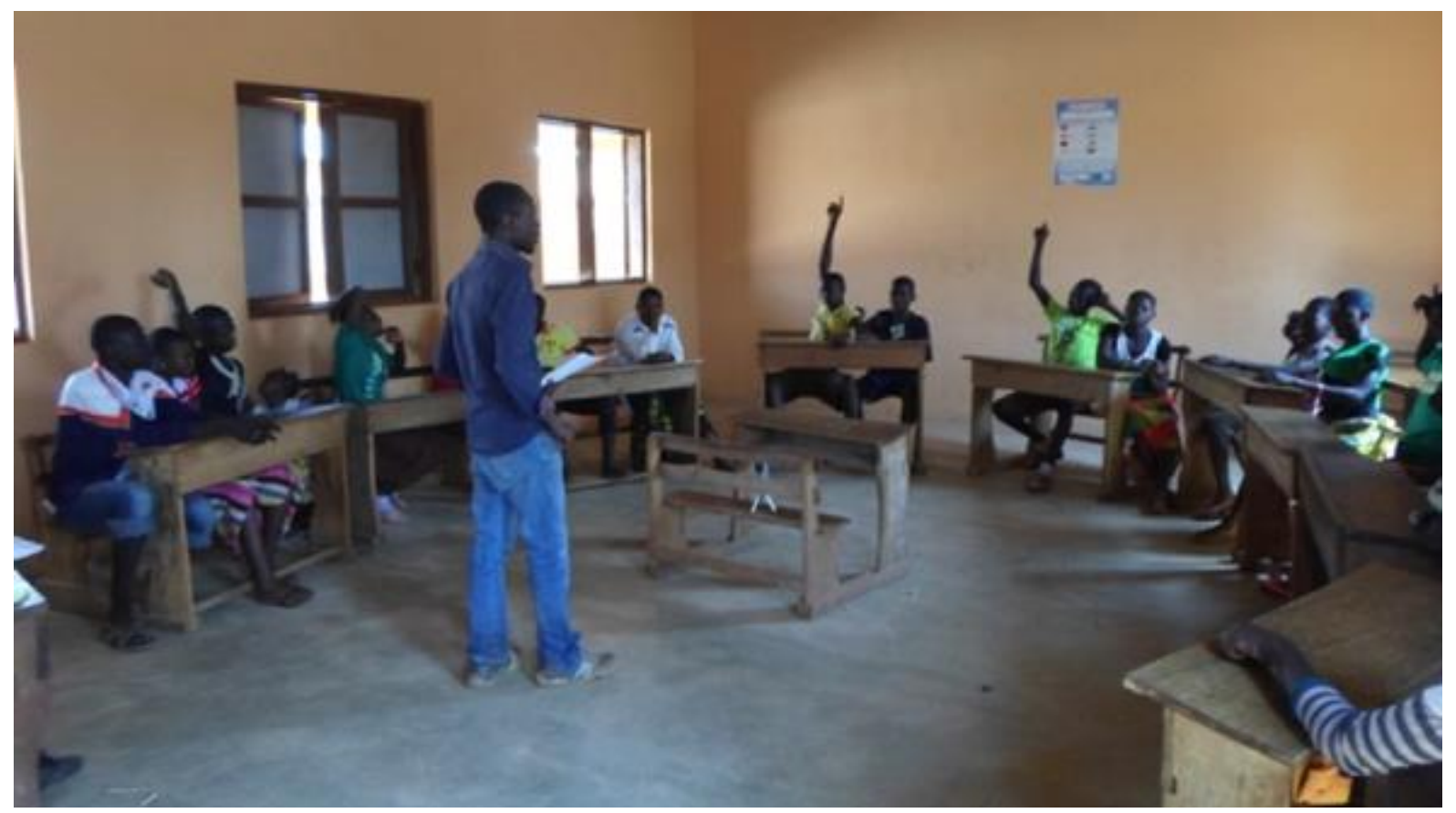

Figure 8: Focus group with Tolon youth led by Alhassan and Zukpeni, convened at a local junior high school. Similar focus groups were conducted at Ziong and Gbungbaliga.

Testimonials. After the intervention, we conducted interviews with six leading figures (two per village), in search of testimonials we might use to promote the project. As it turned out, everyone had something positive to say. One chief remarked, "We learnt a lot from the performance, especially keeping our surroundings clean, sleeping under mosquito [nets] and washing of our hands with soap"; another, "I want to thank your team for the fantastic work you did. Indeed, the performance went well because I learnt many lessons from the dance drama." Another resident observed: "The whole performance was great, especially the Malaria and Cholera songs. It reminded us of the Dagbon tradition and triggered us to change our attitudes towards healthy living." Another said: "Oh my God! The performance was one of the best I have ever witnessed. In fact, I had so much fun and education on malaria and cholera prevention."

While of limited statistical validity, these personal perspectives offer a humanistic response absent from numerical tables of data. Amidst the praise, participants sought continuity, indicating that once was not enough: "I can't wait for more performances in this community and beyond", said a chief, while a resident remarked, "If these performances continue, it will help change our attitudes towards our health", and another, "We are looking forward to more performances".

Follow-up Surveys. We returned to conduct another 60 random surveys in each village; we did not attempt either to resurvey those whom we had interviewed the first time around, or survey only those who had attended, in order to be able to understand the extent of diffusion from attendees to non-attendees. Of these 180 individuals, approximately 80 had in fact attended the interventions. All surveys were scanned and coded using CDC's Epi Info software (CDC, 2016).

Finally, we produced descriptive statistics and conducted rigorous correlations, focusing on the two datasets exhibiting maximal contrast: all pre-intervention surveys, and the postintervention surveys of those who actually attended the intervention (we opted to analyze diffusion rates in a later round). 


\section{Interim Results and Reflection}

Survey data largely confirmed our understanding of the low literacy agricultural profile suggested by official reports (Ghana Statistical Service, 2012; Ghana Health Service, 2010). The large majority of subjects had stopped attending school at the primary level, and were either farmers or merchants by occupation. Thus, the performance culture approach to health promotion was indeed indicated.

Impact assessments - both quantitative and qualitative - showed that dance drama interventions produced significant positive change, and indicated that these three village educational performances were effective in raising awareness and changing health behaviors. This confirmed our hypothesis that dance drama is an effective social technology for progress in public health, especially in regions of high illiteracy and poverty rates (for details of this study see Frishkopf, Hamze, et al., 2016).

But qualitative data, extracted from interviews embedded within focus groups, tracking and testimonials, while laudatory, also indicated an implicit deficiency: we had not made allowances for continuity. The project was successful in raising awareness and improving behaviors, towards better health. But there was no guarantee that such changes would be permanent, and - due to cost - the project was not sustainable.

We were determined to provide generous compensation to our professional team members, for whom music is a livelihood. Transportation entailed additional costs; 'roadies' were required as well, to assemble and disassemble the stage, to say nothing of the sound system and its operator, and traditional protocols. In total, the project cost amounted to about 5000.00 CAD per village performance. While we compensated all participants fairly, it was impossible to imagine how we could raise the funds needed to provide such continuity, since the total cost would linearly increase over time.

What was missing, then, was a means of ensuring sustainability and community engagement; while the project proved the efficacy of the dance drama method to raise awareness, instill knowledge, improve attitudes, and change behaviors, time and consequent forgetfulness might easily reverse such gains. The resulting benefits might ultimately be lost with the passing of generations. More importantly the project ought to be more deeply rooted in the community itself.

Indeed, the problem concerned more than just financial sustainability; it concerned also social sustainability through local engagement. We posed as a PAR project, but with what level of participation? Community participation is crucial not only to guide a project, but to ensure its long-term viability, because in supporting itself, the community acts out self-interest, and naturally adapts to changing conditions.

While our team was multinational and participatory - Ghanaians were involved in key artistic and research roles - village-level participation was as yet limited to promotion by opinion leaders, along with the local "warm up" bands. Even if they were Ghanaians from the same ethnic group, the core PAR team were not community members at the village level. Our project could not yet be construed as a self-motivated community addressing and serving itself.

Certainly, our efforts had not been wasted - we had succeeded not only to raise awareness and change attitudes and behaviors, but also to stir enthusiasm for traditional music functioning in this new health promotion role. How to follow up? 


\section{Phase II}

\section{Overview}

As turning a bend in the road reveals new vistas, the answer swung into view: if music and related performance arts had demonstrable value as a social technology for health promotion, the next step was to effect a "technology transfer", by implanting it within each village, to be sustained and nurtured locally. In an effort to create a truly community-based project, whose sustainability would hinge not only on self-motivated community participation (Zakus, 1998) but also on adaptation to local conditions, it would be necessary to launch local, self-reproducing social formations carrying such messages: village-based amateur 'singing and dancing for health' groups, whose performative knowledge - in the twinned domains of both art and health - would be transmitted through oral processes, dynamically adapting to local conditions.

Their interest and enthusiasm having been piqued by our professional performances, residents would, we hoped, enthusiastically join such groups. The professional, urban Ghanaian artists - primarily from YHCG - would now assume a new role as initializers, selecting, equipping and training the new groups, before setting them in motion. Motivated by a sense of obligation to community service, care and pride, and drawn from the local population, these groups would be far better connected to the local population and village life, their performances supporting community integration via traditional culture and health messaging.

Such groups, performing at traditional and civic events without payment, achieve several congruent goals. Reviving traditional performance types, and pride in local culture, they gather multiple generations and catalyze greater social cohesion through performance and participation; they serve as effective community mobilization devices; and they have the potential to become health agents and incorporate health-oriented dance dramas, either in full, or via performance of component songs and dances, into the local oral tradition, to adapt according to needs, and to be sustained through the generations. Thus, absorbed into the fabric of local culture, we believe that sustainable "singing and dancing for health" becomes possible.

Once set in motion, we expect that these groups, their social organization and messages having been inaugurated as new local traditions, will self-reproduce through the usual processes of traditional oral transmission across generations.

We therefore resolved to return to the same villages to establish, equip and train local youth groups - comprising volunteer members eager to participate out of a sense of musical interest, civic duty and cultural pride - to perform traditional Dagomba dances freighted with health promotion messaging.

Thanks to generous grants from folkwaysAlive! and the Department of Music at the University of Alberta respectively, a new Tolon youth group was inaugurated in July 2015. The inauguration of a second group in Ziong followed in March 2016. By contracting the Youth Home Cultural Group to provide training and supply equipment (drums and costumes), we simultaneously helped to support this worthy organization.

The following discussion outlines the process of group formation and launch for Tolon, the largest of the three villages in which we had worked, the closest to Tamale, and the one where a number of team members had extended family and titular connections.

\section{Timeline}

In May 2015, before embarking on the Tolon "singing and dancing for health" youth group project, we once again secured the moral and political support of Tolon's chief (Tolon 
Naa) and village elders, as well as other opinion leaders and Ghana Health Service. Still enthusiastic following the performances of the previous December, the chief was solidly supportive of the project, not only for its potential in health promotion, but also as a means of sustaining traditional culture.

Training and equipment were supplied by the Youth Home Cultural Group. Besides training and performance in traditional music and dance, YHCG also includes training in the manufacture of handicrafts, including drums and costumes, sold to tourists and student visitors, among others. The group was thus eminently well poised to undertake both the training and equipping of the Tolon group. Two of their most experienced teachers were selected to provide two weeks of training: Alhassan Mohammed Assau for dance, and Zakaria Ibrahim for drumming. At the group's home base, members specialized in drum construction and costume tailoring assembled the requisite number of each (Figure 9).

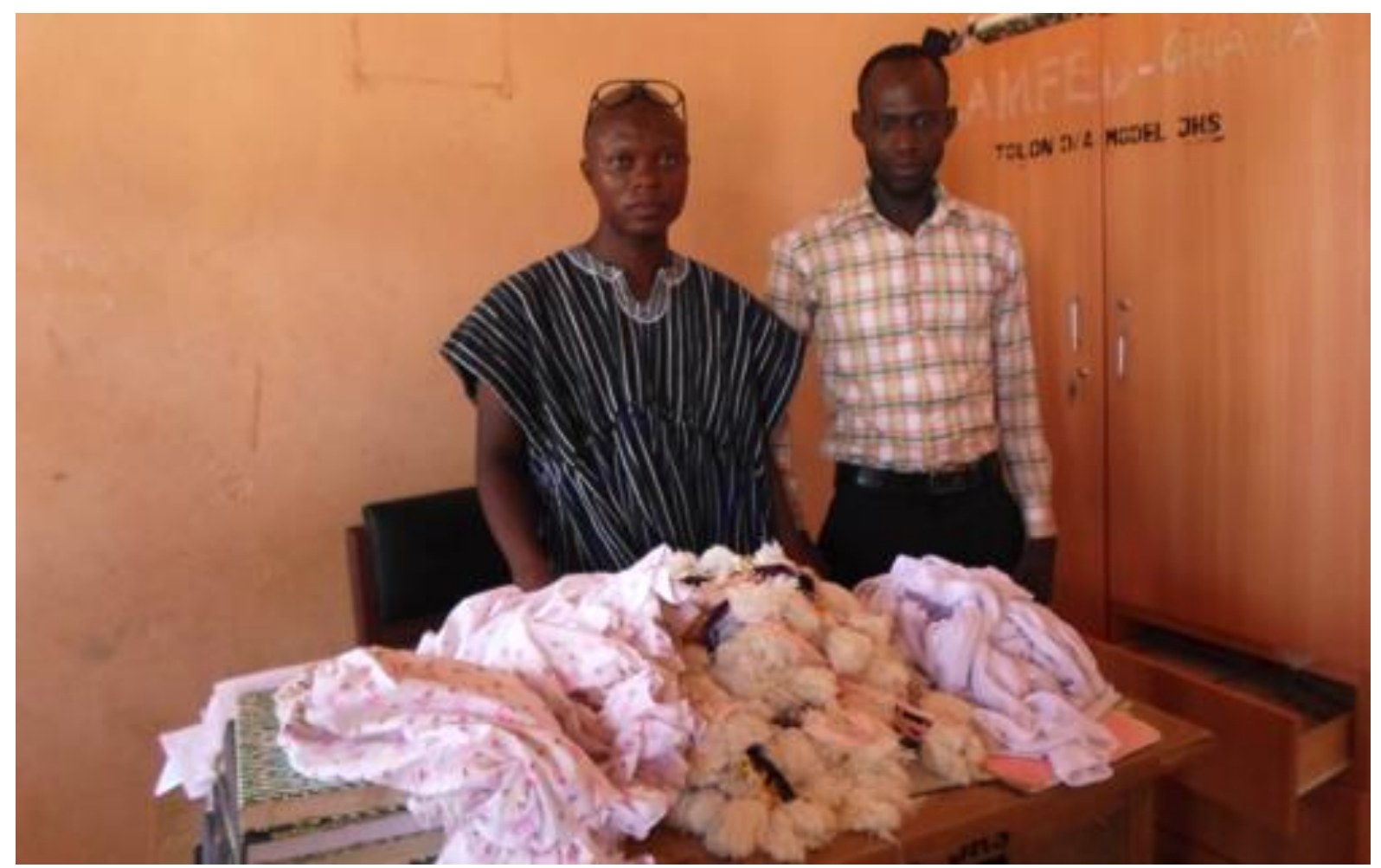

Figure 9: Costumes for the Tolon group.

We returned to the same Tolon junior high school where we had previously conducted focus group discussions with the support of the school's teachers. These teachers now helped audition students who expressed interest in joining the fledgling group. The two YHCG trainers then selected the most talented and dedicated students as members. In consideration of practical limitations on teaching as well as those imposed by standards of traditional performance, we limited the group to 20 members, comprising 10 boys and 10 girls to assure gender balance.

There followed two intensive weeks of training, under the expert tutelage of the two instructors, with superb support from Sulemana Abu. We also engaged researcher Ibrahim Zukpeni to document the entire process with video and still camera recordings (Zukpeni, 2015a). The total cost of equipment, training, and documentation came to around 5000.00 CAD per group, almost precisely the cost of a single village performance. 
The youth were taught two traditional dances presented within the dance dramas: Tora (for the girls) and Bamaya (for the boys). These dances, like those of other ethnic groups in Ghana, are multi-art, combining poetry, song, drumming, and dance. As in many other rural areas in the Dagomba region, their performance had drastically declined in recent years, such that the younger generation no longer knew them, though some of the parents did. The traditional drumming and dance was coupled with songs based on proverbs, selected or revised for their relevance to health education and promotion. Some of the newly-composed lines refer directly to team members, thus strengthening social connection through song.

\section{Bamaya song: \\ Denyeli nyegsaa dahama $n$ kani anduni y anima denveli nyagsa dahama $n$ kani, Niri ghun jaa niri ghun jaa a sheela niri ghun jaa ghuni $m$ bangda atuun tumsa, onaa paa yaa o naa paa yaa a sim nig baa ka dem korigi adem naa paaya and sabtaa yeai yi yi sabtaa begu neeya.}

Meaning: Good things are so sweet but difficult to come by; those who dislike you will always look for your downfall; tell me where my enemy would have had me if not through my friends? The day of hygiene and cleanness has broken; let's all uphold and defend it.

Note: Except for the newly composed final line, this indigenous Bamaya song consists entirely of proverbs:

"Good things are so sweet but difficult to come by," meaning: nothing good comes easily.

"Those who dislike you will always look for your downfall," meaning, in this context: mosquitoes and lack of hygiene will cause troubles for people.

"Tell me where my enemy would have had me if not through my friends?", meaning: Those who know your secrets are responsible for your troubles; in this context these are mosquitoes and dirt, enemies that live with humans and cause disease.

The teachers continued to support us by providing their junior high school as a location for training (Figure 10), and finally as the site of the group's inauguration in a public performance that took place in July 2015. Furthermore, they arranged for on-going rehearsal space on the school grounds, and provided a room where drums and costumes could be safely stored when not in use.

An unexpected benefit of this "technology transfer" emerged with the roles enthusiastically assumed by students' parents. Accompanying their children to rehearsals, these parents listening, watching, and remembering the dances from their youth - spontaneously assumed an active supportive role in the training process, and even staged an informal performance of their own (Zukpeni, 2015c). The enthusiasm with which parents willingly and freely participated as both trainers and performers - due to their perception of traditional music as a means to sustain cultural values - underscores the potential of this music and associated community strategy to 
strengthen social bonds as well as cultural continuity, providing a secure path for its own transmission into the future.

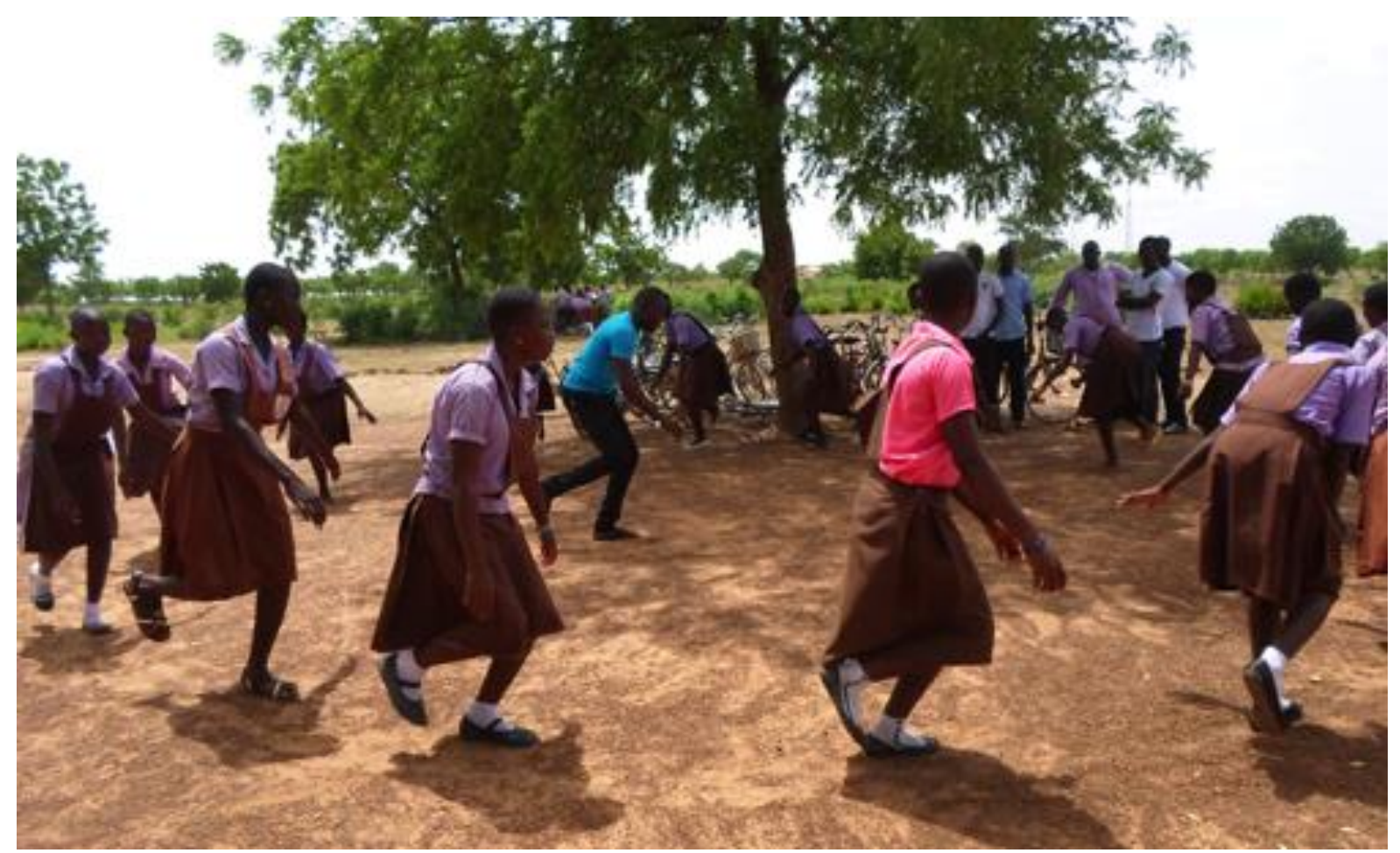

Figure 10: Training the Tolon group; a rehearsal on the school grounds.

The group was formally inaugurated at the school grounds in July 2015 with great fanfare (Figure 11), including speeches from elders and teachers and a spectacular public performance, witnessed by all the students (Zukpeni, 2015b). Thus, the group officially assumed a respected place within the village's social space. Since then regular rehearsals have continued; in November 2015, the group staged a major music-health performance at the palace of the chief, who offered stirring remarks on the importance of maintaining traditional music culture, indicating that while such music - being repurposed to carry health messages - is in some respects an innovation, it is nevertheless cherished as a revival of tradition (Ewenson, 2016). 


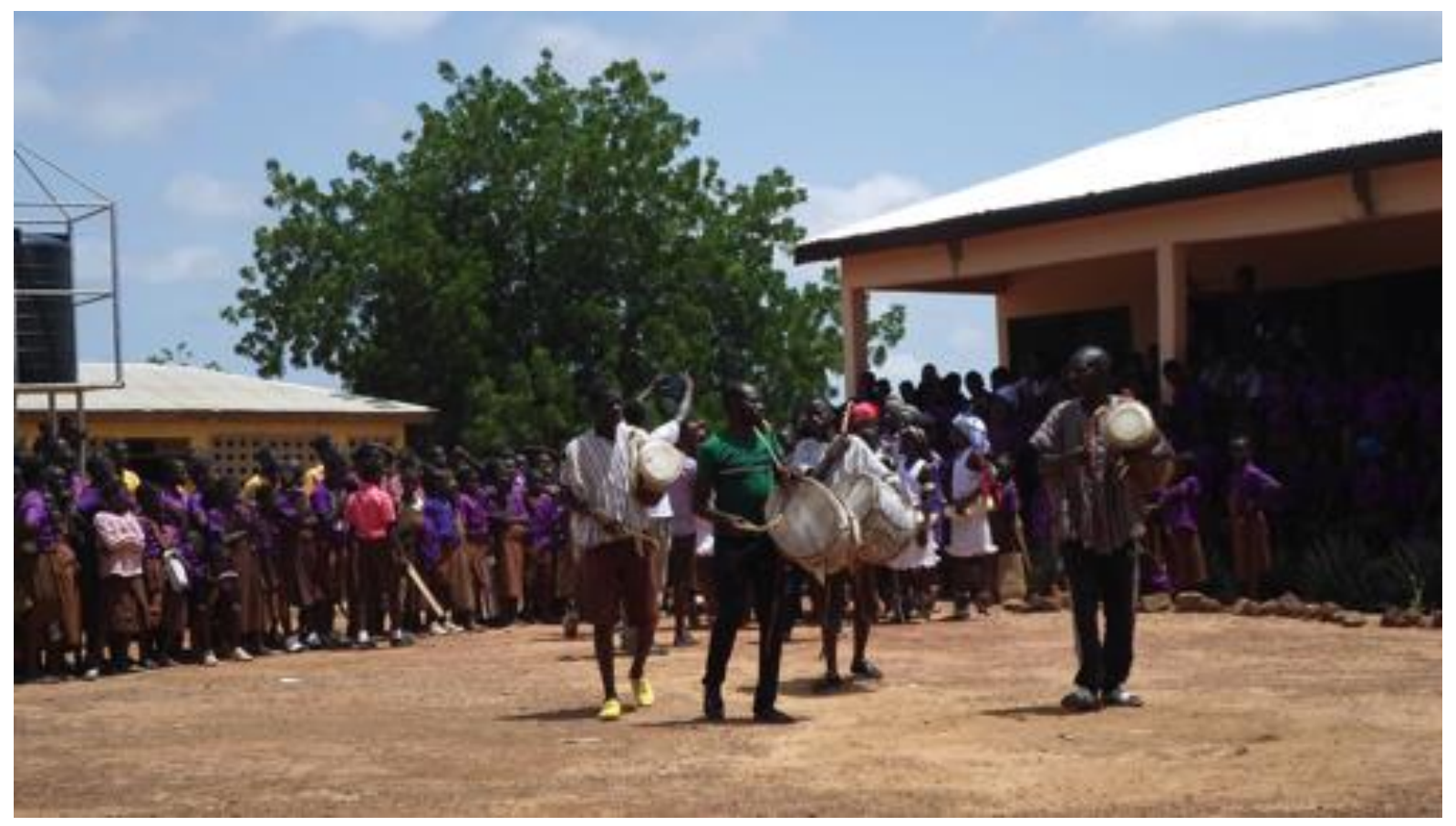

\section{Figure 11: Inauguration day}

Next steps involve qualitative monitoring and evaluation, including a longitudinal study design approach similar to that of Phase I. We plan to conduct several rounds of KAP surveys, completed by respondents selected at random from a variety of locations, including markets, community centers, and schools, at different times of the day, in order to assess improvements in health knowledge, attitude, and practice. We will also conduct focus groups with group members to record their reactions to the program, discover what they have learned, and gather feedback on the new groups, assess motivation and transmission, and gauge how their effectiveness and sustainability could be enhanced.

\section{Concluding Remarks}

Give a man a fish and you feed him for a day. Teach a man to fish and you feed him for a lifetime. Not only do dance dramas convey information sensitizing attendees to health issues, they do so in an atmosphere charged with emotion and social solidarity. The co-presence of a large fraction of the community reinforces health messaging, implicitly affirmed through attendance, while simultaneously supporting a social cohesion infused with health issues at its core. While some social health progress may require more expensive, material interventions, it seems clear that where progress in global health depends primarily on behavioral change, music and dance offer a powerful force to achieve it. By including communities, PAR methods provide a strategy for guiding interventions so as to maximize their impact.

However, it was equally clear that one-off performances by community outsiders, while impactful in conveying health information and stirring local interest, are insufficient. This is because they are unsustainable without a continual inflow of resources, and - even then - they are somewhat disconnected from the village community itself. Rather, they served to establish a launching pad for local, amateur "singing and dancing for health" groups, sustainably supported by the community, integrated within (and strengthening) its social fabric.

Socially, culturally, and performatively, such groups sustain and are sustained by local oral tradition. We hope they will become new traditions, cherished institutions for self-care, 
passed down through the generations, for the sake of better health, and for the revival of cultural continuity as a means of affirming a shared identity and thereby increasing social cohesion. Integral to the community, rather than outside agents, they will require few on-going financial resources; furthermore, as an integral social component, they adapt naturally to social changes as required.

Playing the role of initializer, our team has thus far established two such groups, which should now be able to operate autonomously without significant inputs, material or informational, for some years to come. We will continue to monitor them from time to time, and to offer advice and assistance where needed. But our hope is that we have now planted the seeds of a new, robust tradition combining performance and health promotion that is self-sustaining, at least in the near term. While there is always a risk that the seed may not sprout, or that the resulting tree may wither, the opposite may also occur: like a banyan, these implanted groups may thrive and spread, inspiring new ones in neighboring villages. Whether our hopes will be realized remains to be verified through longitudinal research, but this experiment in the revival and modification of local oral tradition towards better health, if successful, should have tremendous implications for health promotion. Furthermore, we believe that these methods can be transposed to other rural societies likewise characterized by participatory musical traditions, leading to improved community health whenever behavior is a primary determinant, as is so often the case (WHO, 2002). Further research is required to document the processes involved, their strengths and weaknesses, and to suggest strategies for overcoming the latter. But we are optimistic, and we are looking forward to more success. 


\section{References}

Ansu-Kyeremeh, K. (2005). Indigenous communication in Africa: Concept, applications, and prospects. Accra: Ghana Universities Press.

Asante, M. K. (2004). Afrocentricity and communication in Africa. In C. Okigbo \& F. Eribo (Eds.), Development and Communication in Africa (pp. 3-13). Lanham, MD: Rowman $\&$ Littlefield.

Barlocco, F. (2010). The village as a 'community of practice': Constitution of village belonging through leisure sociality. Bijdragen Tot de Taal-, Land-En Volkenkunde, 166(4), 40425.

Barz, G. F. (2006). Singing for life: HIV/AIDS and music in Uganda. New York: Routledge.

Barz, G. F., \& Cohen, J. M. (2011). The culture of AIDS in Africa: Hope and healing in music and the arts. Oxford: Oxford University Press.

Bunton, R., \& Macdonald, G. (2002). Health promotion: Disciplines, diversity, and development. London \& New York: Routledge.

CDC. (2016, May 31). Epi Info. Retrieved from https://www.cdc.gov/epiinfo/ index.html.

Chernoff, J. M. (1979). African rhythm and African sensibility: Aesthetics and social action in African musical idioms. Chicago: University of Chicago Press.

Cole, C. M. (2001). Ghana's concert party theatre. Bloomington, IN: Indiana University Press.

Corcoran, N. (2007). Communicating health strategies for health promotion. Los Angeles: SAGE.

Corke, P. (2000). The drums of Dagbon. Chicago: Home Vision.

Dagbani. (2016, June 2). Ethnologue. Retrieved from http:// www.ethnologue.com/language/dag

Durkheim, É. (1964). The division of labor in society. New York: Free Press of Glencoe.

Ewenson, D. (2016). Tolon Naa Interview after Tolon Youth Group Performed (Nov 2015). Retrieved from https://www.youtube.com/watch?v= prMVwHB_kIc\&feature=youtu.be

Fals-Borda, O. (2005). Participatory action research. In B. Cooke \& J. W. Cox (Eds.), Fundamentals of action research volume II, varieties and workplace applications of action research (pp. 3-9). London: SAGE.

Ford, N., Williams, A., Renshaw, M., \& Nkum, J. (2005). Communication strategy for implementing community IMCI. Journal of Health Communication, 10 (5), 379-401.

Freedman, A. M., Miner, K. R., Echt, K. V., Parker, R., \& Cooper, H. L. F. (2011). Amplifying diffusion of health information in low-literate populations through adult education health literacy classes. Journal of Health Communication, 16(3), 119-33.

Frishkopf, M. (2017). Giving voice to health: 'Sanitation' in Liberia. Journal of Folklore Research.

Frishkopf, M., Abu, S., Mubarak, A., Zukpeni, I. A., Hamze, H., \& Zakus, D. (2016). Singing and Dancing for Health: Traditional Music and Dance for Health Education and Promotion in Rural Northern Ghana. Retrieved from https://www.artsrn.ualberta.ca/fwa_mediawiki/index.php?title= Singing_and_Dancing_for_Health:_Traditional_music_and_dance_for_health_education_and_promotion_in_rural_northern_Ghana

Frishkopf, M., Hamze, H., Alhassan, M., Zukpeni, I. A., Abu, S., \& Zakus, D. (2016). Performing arts as a social technology for community health promotion in northern Ghana. Family Medicine and Community Health, 4(1), 22-36. 
Frishkopf, M., \& Morgan, S. (2013a). Sanitation and safe water in Liberia (Music Video). Retrieved from http://www.youtube.com/watch?v= AmCk4WHPfSU\&feature=youtube_gdata_player.

Frishkopf, M., \& Morgan, S. (2013b). Sanitation and safe water in Liberia (Documentary). Retrieved from http://www.youtube.com/watch?v= 5eDal4NaYbw\&feature=youtube_gdata_player.

Ghana Health Service. (2010). The health sector in Ghana: Facts and figures. Accra: Ghana Health Service.

Ghana Statistical Service. (2012). Population and housing census: Summary report of final results. Accra: Ghana Statistical Service.

Glanz, K., Rimer, B. K., \& Viswanath, K. (2008). Health behavior and health education: Theory, research, and practice. San Francisco, CA: Jossey-Bass.

Kawachi, I., \& Kennedy, B. P. (1997). Health and social cohesion: Why care about income inequality? BMJ (Clinical Research Ed.), 314(7086), 1037-1040.

Kawachi, I., Kennedy, B. P., Lochner, K., \& Prothrow-Stith, D. (1997). Social capital, income inequality, and mortality. American Journal of Public Health, 87(9), 1491-1498.

Kemmis, S., \& McTaggart, R. (2005). Participatory action research: Communicative action and the public sphere. In edited N. K Denzin \& Y. S Lincoln (Eds.), The SAGE Handbook of Qualitative Research (pp. 559-603). Thousand Oaks: SAGE Publications.

Kinney, S. 1970. Drummers in Dagbon: Role of drummer in Damba festival. Ethnomusicology, 14(2), 258-65.

Locke, D. (1990). Drum Damba: Talking drum lessons. Crown Point, IN: White Cliffs Media Co.

Macdonald, G. (2002). Communication theory and health promotion. In R. Bunton \& G. Macdonald (Eds.), Health promotion: Disciplines, diversity, and development (pp. 197-218). London \& New York: Routledge.

MacGaffey, W. (2013). Chiefs, priests, and praise-singers: History, politics, and land ownership in northern Ghana. Charlottesville, VA: University of Virginia Press.

McAlister, A. L. (1991). Population behavior change: A theory-based approach. Journal of Public Health Policy, 12(3), 345-61.

Moemeka, A. A. (1994). Communicating for development: A new pan-disciplinary perspective. New York: SUNY Press.

National Academy of Sciences. (2012). An integrated framework for assessing the value of community-based prevention. Washington, D.C.: National Academies Press.

Nielsen. (2013). Global Trust In Advertising and Brand Messages. The Nielsen Company. Retrieved from http://www.nielsen.com/us/en/insights/reports/ 2013/global-trust-in-advertising-and-brand-messages.html.

Ocholla, D. (2006). Information Accessibility by the Marginalized Communities in South Africa and the Role of Libraries. Retrieved from http://arizona.openrepository.com/arizona/handle/10150/105134

Oppong, C. (1973). Growing up in Dagbon. Tema: Ghana Publishing Corporation.

Osho, S. A. (2011). The uniqueness of African means of communication in the contemporary World. Retrieved from http://www.culturaldiplomacy.org/ academy/content/pdf/participant-papers/africa/Sulaiman-Osho-Uniqueness-Of-African-Communications-In-Contemporary-World-Case-Study-Of-2011-Egyptian-Revolution.pdf 
Pratt, C. B., Silva-Barbeau, I., \& Pratt, C. A. (1997). Toward a symmetrical and an integrated framework of norms for nutrition communication in sub-Saharan Africa. Journal of Health Communication, 2(1), 43-58.

Puska, P., Koskela, K., McAlister, A., Mäyränen, H., Smolander, A., Moisio, S., Viri, L., Korpelainen, V., \& Rogers, E. M. (1986). Use of lay opinion leaders to promote diffusion of health innovations in a community programme: Lessons learned from the North Karelia Project. Bulletin of the World Health Organization, 64(3), 437-46.

Rainey, D. W., \& Larsen, J D. (2002). The effect of familiar melodies on initial learning and long-term memory for unconnected text. Music Perception, 20(2), 173-86.

Rogers, E. M. (1983). Diffusion of innovations. New York \& London: Free Press \& Collier Macmillan.

Schramm, K. (2000). The politics of dance: Changing representations of the nation in Ghana. Afrika Spectrum, 35(3), 339-358.

Staniland, M. (1975). The lions of Dagbon: Political change in northern Ghana. Cambridge: Cambridge University Press.

Ugboajah, F. O. (1985). 'Oramedia' in Africa. In F. O. Ugboajah (Ed.), Mass Communication, Culture, and Society in West Africa (pp. 165-176). Munich \& New York: Hans Zell Publishers.

Warwick, D. P. (1983). The KAP survey: Dictates of mission versus demands of science. Cambridge, MA: Harvard Institute for International Development.

Weare, K. (2002). The contribution of education to health promotion. In R. Bunton \& G. Macdonald (Eds.), Health promotion: Disciplines, diversity, and development (pp. 102-125). London \& New York: Routledge.

Wenger, E. (1998). Communities of practice: Learning, meaning, and identity. Cambridge: Cambridge University Press.

WHO. (2002). The world health report 2002: Reducing risks, promoting healthy life. Geneva: World Health Organization. Retrieved from http:// site.ebrary.com/id/10019887.

WHO. (2008). Advocacy, communication and social mobilization for TB control: A guide to developing knowledge, attitude and practice surveys. Geneva: World Health Organization. Retrieved from http:// whqlibdoc.who.int/publications/2008/9789241596176_eng.pdf

WHO. (2016, May 17). Health promotion. Retrieved from http://www.who.int/ topics/health_promotion/en/

Wilkinson, R. G. (1997). Comment: Income, inequality, and social cohesion. American Journal of Public Health, 87(9), 1504-1506.

Wimbush, E., MacGregor, A., \& Fraser, E. (1998). Impacts of a national mass media campaign on walking in Scotland. Health Promotion International, 13(1), 45-53.

YHCG. (2016, June 2). Youth Home Cultural Group. Retrieved from http://www.yhcg.net/

Zakus, D. (1998). Resource dependency and community participation. Social Science and Medicine, 46(4-5), 475-494.

Zukpeni, I. A. (2015a). Rehearsal. Retrieved from https://www.youtube.com/ watch?v=qpN8ZunZMIo\&feature $=$ youtu.be

Zukpeni, I. A. (2015b). Inauguration Ceremony. Retrieved from https:// www.youtube.com/watch?v=EOrDN9dJ_B4\&feature=youtu.be

Zukpeni, I. A. (2015c). Parents Performances. Retrieved from https:// www.youtube.com/watch?v=5w_POqho5rQ\&feature=youtu.be 